\title{
Ultrasound microbubbles combined with the $N F \kappa B$ binding motif increase transfection efficiency by enhancing the cytoplasmic and nuclear import of plasmid DNA
}

\author{
QING DENG，JIN-LING CHEN，QING ZHOU，BO HU，QIAN CHEN，JIA HUANG and RUI-QIANG GUO \\ Department of Ultrasound Imaging, Renmin Hospital of Wuhan University, Wuhan, Hubei 430060, P.R. China
}

Received May 22, 2013; Accepted August 28, 2013

DOI: $10.3892 / \mathrm{mmr} .2013 .1672$

\begin{abstract}
Inefficient gene delivery poses a challenge for non-viral gene therapy. Cytoplasmic and nuclear membrane barriers are responsible for the inefficiency as they restrict the import of exogenous genes. The present study aimed to improve the transfection efficiency using a novel gene delivery system, which consisted of two components: ultrasound microbubbles and the nuclear factor $\kappa \mathrm{B}(\mathrm{NF} \kappa \mathrm{B})$ binding motif. Ultrasound-targeted microbubble destruction (UTMD) was used to enhance the cytoplasmic import of plasmids and the NFKB binding motif was added to promote the nuclear intake of the plasmid from the cytoplasm. In the present study, human umbilical vein endothelial cells were transfected using UTMD with two different Cy3-labeled plasmids, phSDF-1 $\alpha$ and phSDF- $1 \alpha-\mathrm{NF} \kappa \mathrm{B}$. phSDF- $1 \alpha-\mathrm{NF} \kappa \mathrm{B}$ was constructed by inserting a specific DNA targeting sequence (five optimal repeats of the binding motif for the inducible transcription factor $\mathrm{NF \kappa} B$ ) into phSDF-1 $\alpha$. The nuclear import and gene expression efficiency of phSDF-1 $\alpha-\mathrm{NF} \kappa \mathrm{B}$ were compared with those of phSDF-1 $\alpha$ to investigate the effect of the NFkB binding motif on transfection. The results showed that UTMD significantly increased the cytoplasmic intake of pDNA and maintained high cell viability. The nuclear import and gene expression of phSDF-1 $\alpha-\mathrm{NF} \kappa \mathrm{B}$-transfected cells were significantly higher than those transfected with phSDF-1 $\alpha$. Compared with the NFKB-free plasmids, the quantity of $\mathrm{NF} \kappa \mathrm{B}$ plasmids in the nucleus increased 6.5-fold and the expression of SDF-1 $\alpha$ was 4.4 -fold greater. These results suggest that UTMD combined with NFKB binding motif significantly improve transfection efficiency by enhancing the cytoplasmic and nuclear import of exogenous plasmid DNA.
\end{abstract}

Correspondence to: Dr Rui-Qiang Guo, Department of Ultrasound Imaging, Renmin Hospital of Wuhan University, 238 Jiefang Road, Wuhan, Hubei 430060, P.R. China

E-mail: guorq.wh.edu@hotmail.com

Key words: ultrasound microbubbles, $\mathrm{NF \kappa B}$, nuclear import, gene delivery

\section{Introduction}

A safe and efficient gene transfer system has always been the aim of gene therapy. The clinical application of viral vectors is limited due to the potential safety problems, although these vectors provide high gene transfection efficiency and the possibility of stable gene expression. Over the past three decades, numerous non-viral carriers have been studied and produced to replace viral vectors. However, the transfection efficiency was not desirable due to extracellular and intracellular obstacles during gene delivery $(1,2)$. The cytoplasmic and nuclear membranes are two of the greatest barriers $(3,4)$. To improve the transfection efficiency, various approaches have been investigated for entering the cell and nuclear membrane barriers (4-6).

As a novel non-viral gene delivery system, ultrasoundtargeted microbubble destruction (UTMD) appears to be a promising technology. Previously, numerous studies demonstrated improved gene transfer in the presence of ultrasound and microbubbles (7-9). In addition, as a physical method, the ultrasound-microbubble technology showed superiority over other non-viral gene carriers with the ability to target gene delivery to a specific area. This possibility provides extensive application prospects of the technique for in vivo studies (10). Therefore, in the present study, UTMD technology was utilized to promote the entry of plasmid DNA (pDNA) into the cytoplasm.

The poor nuclear import rate is another critical challenge for non-viral gene delivery methods. Previous studies showed that directly micro-injecting pDNA into the cytoplasm only resulted in $\sim 3 \%$ nuclear import and low expression (11). Therefore, breaking through the nuclear membrane barrier and promoting nuclear import are crucial for gene transfer. In the early stage, numerous nuclear localization signals (NLSs), such as the SV40 large T antigen, have been used to promote gene import into the nucleus of non-dividing cells (12); however, the gene transfection efficiency was not as high as expected. Nuclear factor $\kappa \mathrm{B}(\mathrm{NF} \kappa \mathrm{B})$, which contains a natural NLS and shuttles between the cytoplasm and nucleus, has been found to facilitate the nuclear import of pDNA (13).

In the present study, a specific DNA-targeting sequence (five optimal repeats of the NFKB binding motif) was designed to embed into pDNA-containing therapeutic genes. The NFкB binding motif is recognized by and binds to $\mathrm{NF \kappa B}$, which 
activates the nuclear-protein guided intracellular trafficking of the pDNA and may improve the nuclear intake and transfection efficiency. To further increase the transfection efficiency, the $\mathrm{NF \kappa B}$ binding motif was combined with UTMD. It was hypothesized that UTMD enhances the cellular uptake of pDNA and the NFKB binding motif promotes the nuclear import of pDNA. Thus, the transfection efficiency would be markedly increased by combining these two approaches.

\section{Materials and methods}

hSDF-1 $\alpha$ plasmid construction. The primers for cloning human SDF-1 $\alpha$ (hSDF-1 $\alpha$ ) were synthesized by Invitrogen Life Technologies (Shanghai, China). The primers were as follows: Forward: 5'-ATGAACGCCAAGGTCGTGGTCG-3'; reverse: 5'-TCACATCTTGA ACCTCTTGTTT-3'. Total mRNA from human fibroblasts was extracted using TRIzol reagent (Invitrogen Life Technologies, New York, NY, USA) and reverse transcription-polymerase chain reaction (RT-PCR) was used to obtain the hSDF-1 $\alpha$ DNA. Following this, pcDNA3.1(-) vectors (Invitrogen Life Technologies, New York, NY, USA) were extracted using $N h e \mathrm{I} / E c o$ RI restriction enzymes and the RT-PCR products were inserted into the same restriction sites using T4-DNA ligase.

hSDF-1 $\alpha-N F \kappa B$ plasmid construction. The $5 \mathrm{X}$ NFкB fragment was as follows: 5'-CTGGGGACTTTCCAG CTGGGGACTTTCCAGCTGGGGACTTTCCAGCTGGGG ATTTCCAGCTGGGGACTTTCCAGCT-3' (each underlined section represents one $\mathrm{NF}_{\kappa} \mathrm{B}$ binding motif and five 10-bp $\mathrm{NF \kappa B}$ sites were separated by the 5-bp optimized spacer AGCTG to ensure the best structural fit with $\mathrm{NF \kappa B}$ ). The fragment was designed, as described previously (13) and added to the hSDF- $1 \alpha$ primers. The hSDF- $1 \alpha-N F \kappa B$ DNA was obtained as described above. Following digestion using BamHI/HindIII restriction enzymes, the $\mathrm{hSDF}-1 \alpha-\mathrm{NF} \kappa \mathrm{B}$ DNA was cloned into the same restriction site of the pcDNA3.1(-) vector using T4-DNA ligase (Fig. 1).

Ligation products were transformed into the E.coli strain DH5a for amplification and then isolated and purified using a Qiagen Endofree Plasmid kit (Qiagen, Hilden, Germany).

Plasmid labeling. Plasmids were labeled with Cy3 using the Label IT Tracker Intracellular Nucleic Acid Localization kits (Mirus Bio LLC., Madison, WI, USA), according to the manufacturer's instructions. The reagent:plasmid weight ratio was 1:2 and the mixture was purified by ethanol precipitation and then dissolved to a concentration of $1 \mathrm{mg} / \mathrm{ml}$.

Cell culture. Human umbilical vein endothelial cells (HUVECs) were supplied by Doctor Jinyue Hu, Central Laboratory of Renmin Hospital, Wuhan University (Wuhan, China). The HUVECs were cultured in endothelial cell medium (ECM, ScienCell Research Laboratories, Carlsbad, CA, USA) containing $10 \%$ fetal bovine serum and $1 \%$ endothelial cell growth supplement. The cells were maintained in $10-\mathrm{cm}$ culture dishes at $37^{\circ} \mathrm{C}$ in a humidified $5 \% \mathrm{CO}_{2}$ atmosphere. Confluent cells were trypsinized and seeded at a density of $2 \times 10^{5}$ cells per well (2 ml ECM) in 6-well plates (Corning Inc., Corning, NY, USA) $24 \mathrm{~h}$ prior to transfection.

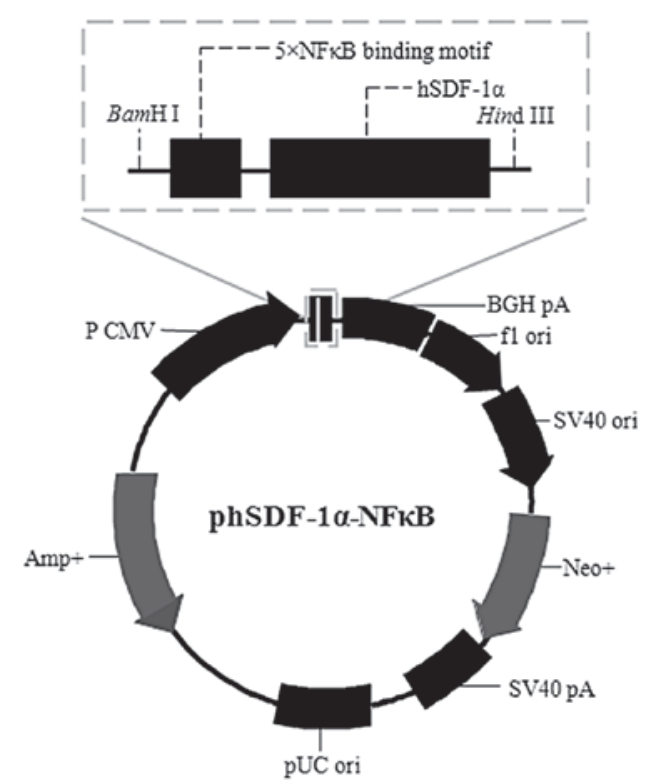

Figure 1. Structure of the hSDF-1 $\alpha$-nuclear factor $(\mathrm{NF}) \kappa \mathrm{B}$ plasmid. The $5 \mathrm{X}$ NFкB binding motif (five repeats of 5'-GGGACTTTCC-3') is inserted downstream of the CMV promoter. The sequence encoding hSDF-1 $\alpha$ cDNA follows the $5 \mathrm{X}$ NFKB binding motif.

Microbubble preparation. A commercially available second-generation contrast agent, SonoVue (Bracco, Geneva, Switzerland), was used in this study. Following the addition of $5 \mathrm{ml}$ normal saline solution and vigorous oscillation, a suspension containing $\sim 2 \times 10^{8}$ microbubbles per ml was obtained. The microbubbles were filled with sulfur hexafluoride gas and encapsulated by a thin and flexible monolayer of phospholipids. The diameters of the microbubbles were $0.8-10 \mu \mathrm{m}$ and the majority were $2-5 \mu \mathrm{m}$.

Ultrasound-and microbubble-mediated plasmid transfection. Gene transfection was performed when the cells in the 6 -well plates were $60-70 \%$ confluent. The culture medium was replaced with $4 \mathrm{ml} \mathrm{OptiMEM}{ }^{\circledR}$ medium (Gibco, Grand Island, NY, USA) suspension containing $10 \mu \mathrm{g}$ Cy3-labeled plasmid and various quantities of microbubbles per well prior to transfection. Subsequent to this, ultrasound irradiation was performed on the cell and plasmid-microbubbles suspension using the UGT2007 ultrasound irradiation machine (Ultrasonic Research Institute of Chongqing Medical University, Chongqing, China) with various acoustic intensities and exposure times. The transducer was wrapped with a thin sterile latex sheath and then immersed into the suspension for irradiation (Fig. 2).

To optimize the ultrasound- and microbubble-mediated transfection parameters, a series of variables were tested as follows: i) Microbubble concentration: $0,1 \times 10^{5}, 1 \times 10^{6}, 1 \times 10^{7}$ and $1 \times 10^{8}$ per $\mathrm{ml}$. The acoustic intensity and exposure time were fixed at $1.0 \mathrm{~W} / \mathrm{cm}^{2}$ and $30 \mathrm{sec}$, respectively. ii) Acoustic intensity: $0,0.5,1.0,1.5$ and $2.0 \mathrm{~W} / \mathrm{cm}^{2}$. The microbubble concentration and exposure time were fixed at $1 \times 10^{7}$ microbubbles per $\mathrm{ml}$ and $30 \mathrm{sec}$, respectively. iii) Exposure time: 10, $30,45,60$ and $120 \mathrm{sec}$, with a $20 \%$ duty cycle. The microbubble concentration and acoustic intensity were fixed at $1 \times 10^{7}$ microbubbles per $\mathrm{ml}$ and $1.0 \mathrm{~W} / \mathrm{cm}^{2}$, respectively. 


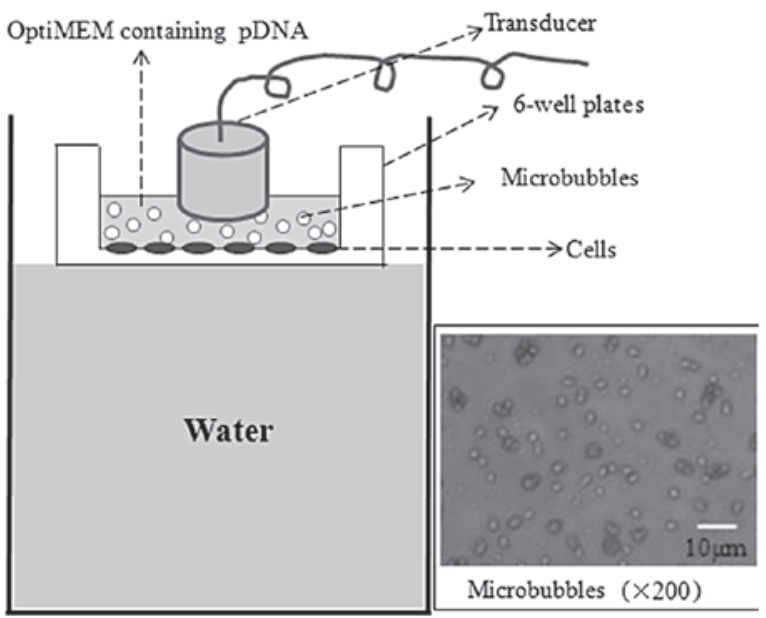

Figure 2. Schematic depiction of the ultrasound microbubble-mediated gene delivery system. The image in the lower right corner shows SonoVue microbubbles (light microscopy; magnification, x200).

The optimal parameters were determined using the criteria of high cell viability and ideal pDNA uptake. Transfections were performed using the determined optimal ultrasound-microbubble transfection condition.

Cell viability. HUVECs were seeded in 96-well plates $\left(5 \times 10^{3}\right.$ cells and $100 \mu \mathrm{l}$ culture medium, per well). The transfections were performed in exactly the same manner as described above. Following incubation at $37^{\circ} \mathrm{C}$ for $24 \mathrm{~h}$, $10 \mu$ l Cell Counting kit-8 (CCK-8, Dojindo Laboratories, Kumamoto, Japan) was added to each well. Following incubation at $37^{\circ} \mathrm{C}$ for $2 \mathrm{~h}$, the absorbance was measured at $450 \mathrm{~nm}$ using an automatic microplate reader (Lambda 1050; Perkin Elmer, Waltham, MA, USA). Four duplicate experiments were performed to reduce random error. Cell viability was calculated as: $\left(\mathrm{OD}_{\text {sample }} / \mathrm{OD}_{\text {control }}\right) \times 100 \%$, where $\mathrm{OD}$ is the optical density.

Cellular uptake of pDNA. To detect the cellular uptake of the plasmid, HUVECs were incubated at $37^{\circ} \mathrm{C}$ for $4 \mathrm{~h}$ subsequent to being transfected with $\mathrm{Cy} 3$-labeled pDNA. Following this, the transfected HUVECs were washed three times with phosphate-buffered saline (PBS; Gibco, Life Technologies, New York, NY, USA) and harvested using trypsin. The number of fluorescent cells was detected using flow cytometry (Beckman Coulter Inc., Brea, CA, USA) and the cellular uptake efficiency was calculated as the percentage of $\mathrm{Cy} 3$-positive cells.

Nuclear uptake of pDNA. The cells were seeded on sterile coverslips that were placed on the bottom of 6-well plates. Transfection was performed with Cy3-labeled phSDF- $1 \alpha$ or phSDF- $1 \alpha-\mathrm{NF} \kappa \mathrm{B}$ plasmids using the same method as described when the cells were $50 \%$ confluent. The transfected cells were incubated for an additional $4 \mathrm{~h}$ in the absence or presence of $20 \mathrm{ng} / \mathrm{ml}$ recombinant human IL-1 $\beta$ (PeproTech, Rocky Hill, NJ, USA) and washed six times with PBS. Cells were then fixed with $4 \%$ paraformaldehyde. DAPI (Beyotime Biotechnology Inc., Nantong, China) was added to clearly stain the nucleus and the cells were washed with PBS six times prior to observation. The subcellular localization of the Cy3-labeled plasmids was observed using fluorescence microscopy (BX61; Olympus, Inc., Tokyo, Japan). The fluorescence intensity (FL) of the whole cell $\left(\mathrm{FL}_{\text {cell }}\right)$ and the nucleus $\left(\mathrm{FL}_{\text {nucleus }}\right)$ was quantified using ImageJ 1.46 software (http://rsb.info.nih.gov/ij). The nuclear uptake efficiency of the pDNA was calculated as $\left(\mathrm{FL}_{\text {nucleus }} / \mathrm{FL}_{\text {cell }}\right) \times 100 \%$.

$R T-P C R$. The mRNA expression of the hSDF-1 $\alpha$ gene was semi-quantitatively analyzed using an RT-PCR kit (Thermo Scientific, Waltham, MA, USA). The primers were as follows: Forward: 5'-TCAGCCTGAGCT ACAGATGC-3' and reverse: 5'-CTTTAGCTTCGGGTCAA TGC-3' for hSDF-1 $\alpha$; forward: 5'-CAAGGTCATCCATGA CAACTTTG-3' and reverse: 5'-GTCCACCACCCTGTTGCT GTAG-3' for glyceraldehyde 3-phosphate dehydrogenase (GAPDH). PCR products were electrophoresed on a $1 \%$ agarose gel and stained with ethidium bromide. GAPDH was used to normalize the cDNA from different samples. The relative expression of hSDF-1 $\alpha$ (hSDF-1 $\alpha /$ GAPDH) was measured using a gel imaging analysis system (Geliance 200; Perkin Elmer).

Western blot analysis and enzyme-linked immunosorbent assay (ELISA). Qualitative and quantitative analysis of the hSDF-1 $\alpha$ protein expression was performed using western blot analysis and ELISA. Protein samples were extracted from the medium and the cell lysis product and then separated using $10 \%$ sodium dodecyl sulfate-polyacrylamide gel electrophoresis. The separated proteins were transferred to polyvinylidene fluoride membranes and incubated with anti-hSDF-1 $\alpha$ antibody (Abcam Inc., Cambridge, MA, USA) at $4^{\circ} \mathrm{C}$ overnight. The membranes were blocked with $5 \%$ non-fat dry milk and incubated with horseradish peroxidase-coupled secondary antibodies for $1 \mathrm{~h}$ at room temperature. The membranes were washed and exposed to X-ray to detect the expression bands. The quantity of SDF- $1 \alpha$ protein was measured using an hSDF-1 $\alpha$ ELISA kit (R\&D Systems, Minneaopolis, MN, USA) according to the manufacturer's instructions. The 96-well polystyrene microplate was coated with a rabbit polyclonal anti-SDF-1 $\alpha$ antibody, and recombinant human SDF-1 $\alpha$ was used as the standard. The results are expressed as the quantity of $\mathrm{hSDF}-1 \alpha / \mathrm{mg}$ protein.

Statistical analysis. Data are expressed as the mean \pm SEM. For analysis of the difference between the two groups, the Student's t-test was performed. For multiple group comparisons, analysis of variance was performed, followed by the Student-Newman-Keuls q-test. $\mathrm{P}<0.05$ was considered to indicate a statistically significant difference.

\section{Results}

Optimization of ultrasound exposure parameters. The ultrasound exposure parameters were optimized to increase the efficiency of the pDNA cellular uptake while minimizing the cytotoxicity mediated by the ultrasound and microbubbles.

The gene delivery efficiency increased with the microbubble concentration but decreased when the microbubble concentration was higher than $1 \times 10^{7}$ microbubbles $/ \mathrm{ml}$. The cell survival rate did not significantly differ as microbubble concentration 
increased from 0 to $1 \times 10^{7} / \mathrm{ml}$; however, a notable decrease occurred when the concentration exceeded $1 \times 10^{7} / \mathrm{ml}$ microbubbles (Fig. 3A). The gene delivery efficiency peaked at $1.5 \mathrm{~W} / \mathrm{cm}^{2}$, and a marked reduction of the cell survival rate occurred at the same acoustic intensity (Fig. 3B). When the exposure time was between 10 and $45 \mathrm{sec}$, gene delivery efficiency increased and reached the maximum level of $74 \%$. The gene delivery efficiency was reduced with further increases in the ultrasound exposure time due to a significant increase in cell death.

For the criteria of cell viability and efficient gene delivery, the optimal exposure parameters in this study were determined to be a microbubble concentration of $1 \times 10^{7} / \mathrm{ml}$, acoustic intensity of $1.5 \mathrm{~W} / \mathrm{cm}^{2}$ and exposure time of $45 \mathrm{sec}$ with a $20 \%$ duty cycle.

Ultrasound and microbubbles enhanced cellular uptake of $p D N A$. As shown in Fig. 4A, when HUVECs were treated with UTMD using the optimal exposure condition described above, the ratio of fluorescent cells was $81 \%$, which was significantly higher than that for the transfection with only ultrasound or with microbubbles alone (11 and $2 \%$, respectively). The cell viability was $>85 \%$ under the optimal exposure conditions. These results indicated that the ultrasound exposure combined with microbubbles was an effective and safe method for gene delivery.

$N F \kappa B$ binding motif promoted the nuclear import of $p D N A$. When activated by IL-1 $\beta$, the nuclear uptake of pDNA in the HUVECs transfected with phSDF- $1 \alpha-\mathrm{NF} \kappa \mathrm{B}$ was 6.5 times greater than that in the HUVECs transfected with phSDF-1 $\alpha$, whereas there was no significant difference between the two groups without IL-1 $\beta$ stimulation (Fig. 4B). The results suggested that the NFKB binding motif significantly promoted the nuclear import of the plasmid but was unable to do so without the stimulation by IL-1 $\beta$. Fig. 5 shows the subcellular localization of Cy3-labeled phSDF-1 $\alpha-\mathrm{NFKB}$ and phSDF-1 $\alpha$ plasmids. The fluorescence intensity in the nucleus of the phSDF- $1 \alpha-\mathrm{NF} \kappa \mathrm{B}$ group was markedly higher than that of the phSDF-1 $\alpha$ group.

Increased hSDF-1 $\alpha$ mRNA expression. HUVECs were transfected with pcDNA3.1 (control), phSDF-1 $\alpha$ or phSDF-1 $\alpha-\mathrm{NF} \kappa \mathrm{B}$ and activated by IL-1 $\beta$ stimulation for $24 \mathrm{~h}$. Subsequent to this, hSDF-1 $\alpha$ mRNA expression was determined using the semi-quantitative RT-PCR. Fig. 6A shows the gene expression of hSDF-1 $\alpha$ and GAPDH. In the pcDNA3.1 (control) group, a weak gene expression was observed as normal vascular endothelial cells were only able to express a small quantity of SDF-1 $\alpha$ following activation by IL-1 $1 \beta$. Fig. 6B shows the relative expression of the hSDF-1 $\alpha$ mRNAs normalized by GAPDH. The relative expression of mRNA in the phSDF- $1 \alpha-\mathrm{NF} \kappa \mathrm{B}$ group was significantly higher than that of the phSDF- $1 \alpha$ group.

Increased $h S D F-1 \alpha$ protein expression. Consistent with the mRNA expression, the SDF-1 $\alpha$ protein level was significantly higher in the phSDF- $1 \alpha-\mathrm{NF} \kappa \mathrm{B}$ group than in the remaining two groups. Western blot analysis data demonstrated that the relative expression of the hSDF- $1 \alpha$ protein in the phSDF- $1 \alpha-N F \kappa B$ group was $\sim 3$ times as high as that of the phSDF-1 $\alpha$ group. Moreover, the quantitative ELISA results
A 80 -

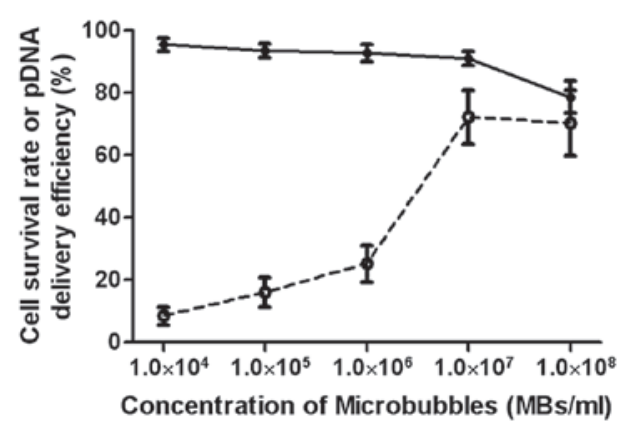

B

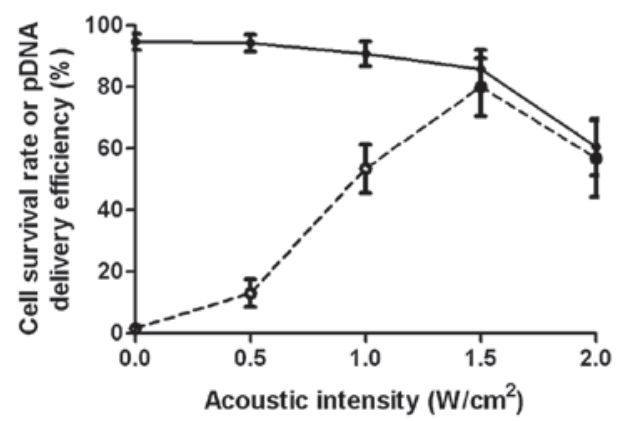

C

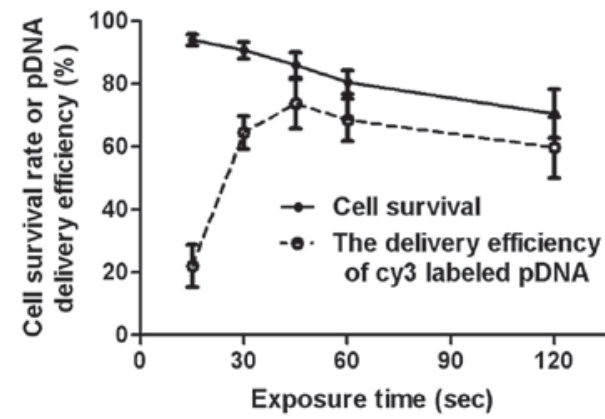

Figure 3. pDNA delivery efficiency and cell viability for various (A) microbubble concentrations, (B) acoustic intensities and (C) exposure times. pDNA, plasmid DNA.

suggested that the expression of the hSDF-1 $\alpha$ protein in the phSDF-1 $\alpha-\mathrm{NFkB}$ group increased 4-fold compared with that in the phSDF-1 $\alpha$ group. (Fig. 7)

\section{Discussion}

Poor transfection efficiency is a great challenge for non-viral gene therapy. The cytoplasmic and nuclear membrane barriers, which seriously restrict the import of exogenous genes, are two key reasons for this inefficiency (14). In the present study, UTMD was combined with the NFKB binding motif to promote the passage of an exogenous gene through the cytoplasmic and nuclear membrane barriers. The results showed that the cytoplasmic and nuclear uptake of the exogenous pDNA significantly increased and the expression of the targeted gene was $\sim 4$-times greater than that of the control.

Over the past two decades, UTMD has been recognized as a valuable method for gene delivery. Various microbubble and ultrasound parameters were investigated to improve the transfection efficiency, although the mechanism has not been clearly defined (15-16). Numerous studies have suggested 
A

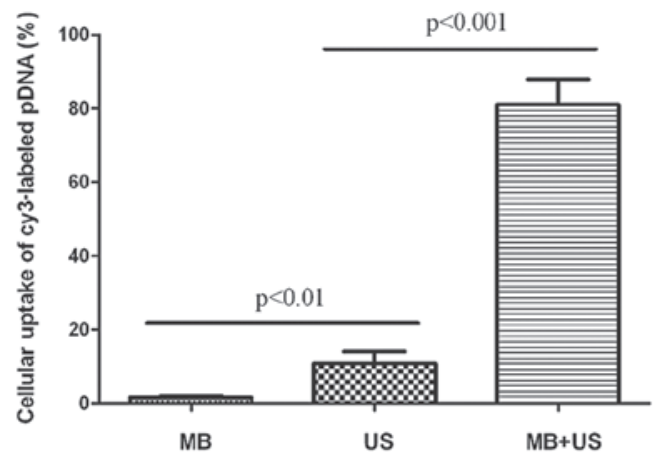

B

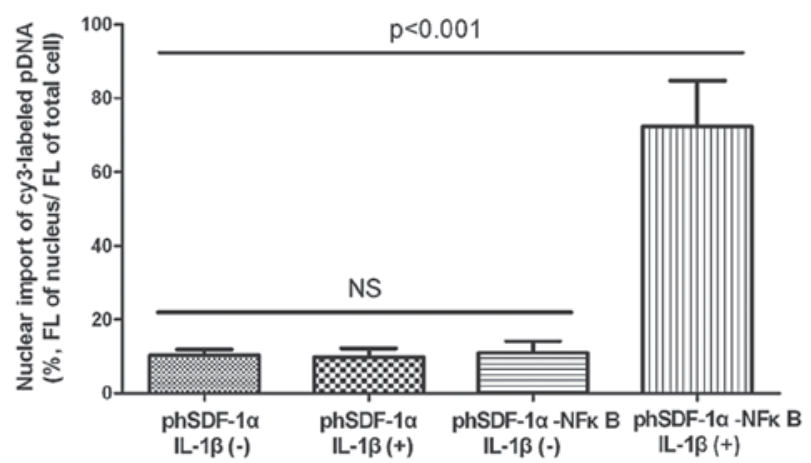

Figure 4. Cellular and nuclear import of pDNA. (A) Efficiency of the cellular uptake of the pDNA with MB, US and the combination of MB with US. (B) Efficiency of the nuclear import of the pDNA with or without the NFאB binding motif in the absence or presence of IL-1 13 . pDNA, plasmid DNA; MB, microbubbles, US, ultrasound, $\mathrm{NF \kappa B}$, nuclear factor-kB; IL-1 $\beta$, interleukin-1 $\beta$; FL, fluorescence intensity; NS, not significant.
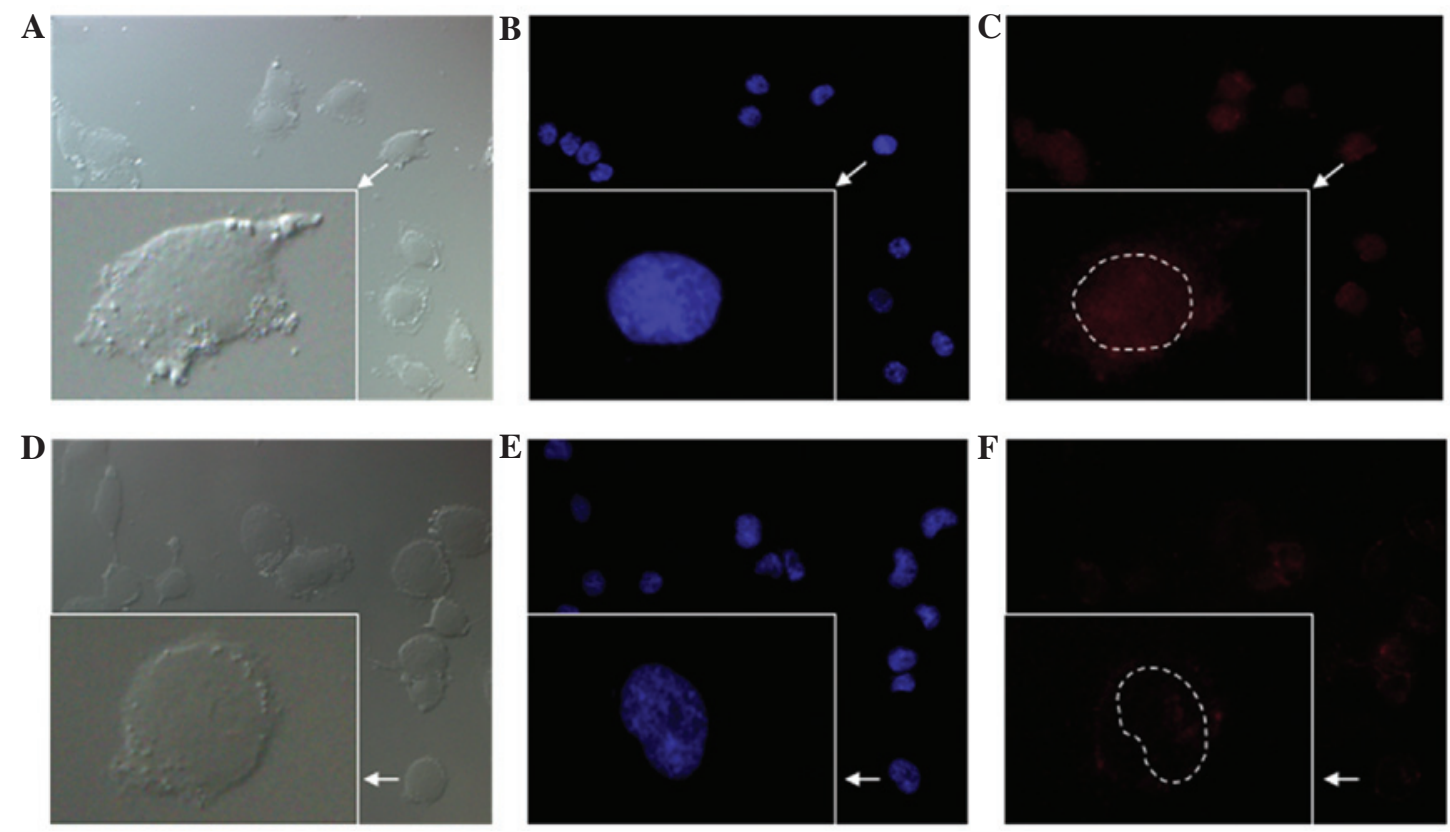

Figure 5. The subcellular localization of the plasmids is observed using fluorescence microscopy. (A-C) HUVECs transfected with Cy3 labeled phSDF-1 $\alpha$-NFkB plasmid. (D-F) HUVECs transfected with Cy3-labeled phSDF-1 $\alpha$ plasmid. (A and D) HUVECs (light microscope; magnification, x400); (B and E) nucleus stained with DAPI (blue); (C and F) the subcellular localization of Cy3-labeled plasmids (red). The image in the left corner (arrow) shows a typical single cell from the field of view of the microscope (BX61; Olympus, Inc., Tokyo, Japan). HUVECs, human umbilical vein endothelial cells; NFkB, nuclear factor-kB.

that the following mechanisms are mostly likely: microbubbles, serving as cavitation nuclei, facilitate cavitation during ultrasound exposure. The microjet and the rupture of microbubbles resulting from cavitation releases large quantities of energy, creating transient and reversible nanopores on the cell membrane, the creation of these pores is termed as 'sonoporation' and has been demonstrated by scanning electron microscopy in previous studies (17). Thus, exogenous pDNA or other molecules enter cells through the nanopores without resulting in irreversible cell damage. In the present study, commercially available SonoVue lipid microbubbles and optimized ultrasound exposure parameters (microbubble concentration of $1 \times 10^{7} / \mathrm{ml}$; acoustic intensity of $1.5 \mathrm{~W} / \mathrm{cm}^{2}$ and exposure time of $45 \mathrm{sec}$ ) were applied for gene delivery. The results showed that ultrasound only marginally increased the gene delivery efficiency (expressed as the percentage of fluo- rescent cells). However, when UTMD was applied, the gene delivery efficiency was significantly improved. The synergistic bioeffect was significantly higher than the ultrasound bioeffect or the microbubble bioeffect alone. When transfection was performed under the optimal ultrasound exposure parameters, Cy3-labeled pDNA was detected in $\sim 81 \%$ of cells while the cell viability was $>85 \%$. This result indicated that UTMD-mediated gene delivery was safe and effective.

Although the entry of exogenous genes into the cytoplasm is essential for transfection, its efficiency is unsatisfactory. The high cytoplasmic import of a gene does not result in high expression. The exogenous pDNA in the cytoplasm is required to enter the nucleus for transcription, rendering the nuclear membrane an insurmountable obstacle for pDNA (18).

The nuclear membrane is a double membrane on the surface of the nucleus and numerous nuclear pore complexes (NPCs) are 




B

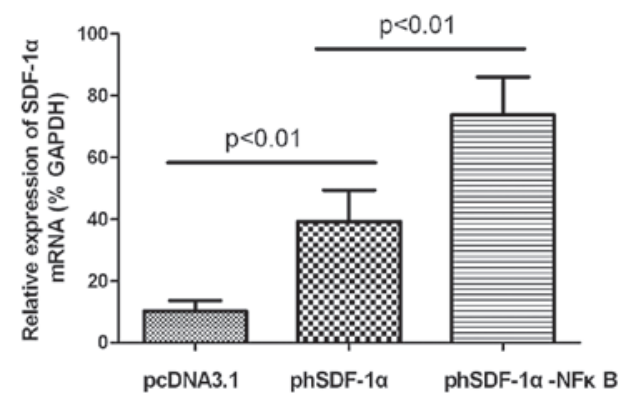

Figure 6. (A) mRNAs of SDF- $1 \alpha$ are assessed using semi-quantitative RT-PCR. Lane 1, transfected with the control plasmid, (pcDNA3.1); lane 2 , transfected with the phSDF-1 $\alpha$ plasmid; lane 3, transfected with the phSDF-1 $\alpha-\mathrm{NF} \kappa \mathrm{B}$ plasmid; lane 4, DNA marker (600 bp); lanes 5-7 are GAPDH. (B) The relative expression of the mRNAs is normalized by

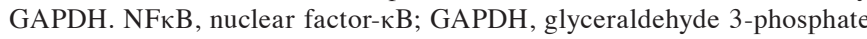
dehydrogenase.

A

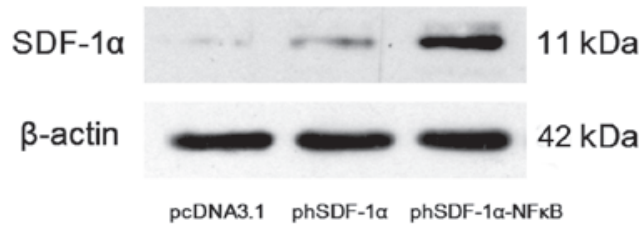

B

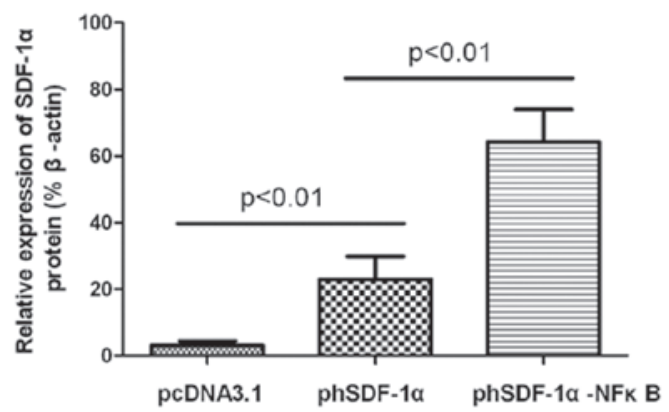

C

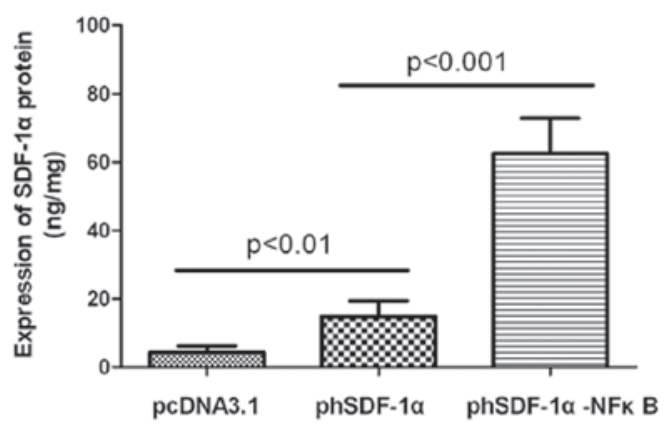

Figure 7. Protein expression of SDF-1 $\alpha$. (A) Western blot analysis of the SDF-1 $\alpha$ protein. Lane 1, transfected with the control plasmid (pcDNA3.1); lane 2 , transfected with the phSDF-1 $\alpha$ plasmid; lane 3 , transfected with the phSDF- $1 \alpha-N F \kappa B$ plasmid. (B) Relative expression of SDF- $1 \alpha$ protein is normalized by $\beta$-actin. (C) Quantitative analysis of the SDF- $1 \alpha$ protein using enzyme-linked immunosorbent assay. distributed on it. NPCs are key in nucleocytoplasmic exchange in eukaryotes and support two modes of transport. Small particles (particles $<9 \mathrm{~nm}$, proteins $<40 \mathrm{kDa}$ and DNA $<300 \mathrm{bp}$ ) pass through the NPCs by passive diffusion and the transportation of large molecules is mediated by nuclear localization signal (NLS) peptides (19). NLS interact with importin- $\alpha$ and $-\beta$ and then form a complex, which is docked to NPCs and shuttled to the inner membrane of the nucleus (20-21). The size of pDNA (usually $\sim 5,000 \mathrm{bp}$ ) renders it highly unlikely to transverse the NPC channels as a free molecule.

To aid pDNA circumvent the nuclear entry bottleneck, considerable efforts have been made to mimic the process of NLS-mediated nuclear import of large molecules. In the early stage, NLS peptides were directly attached to nucleic acid molecules to promote the nuclear uptake of pDNA (22-23). However, the result was unsatisfactory due to the strong interaction between the positively charged peptide and the negatively charged pDNA, which modified the physicochemical properties of the NLS peptide and the pDNA. Certain nucleotide sequences that interacted with endogenous NLS-containing proteins were inserted into pDNA and this addition proved to be beneficial for nuclear import (24). However, the benefit from the addition of this device in terms of gene transfection efficiency was also not as high as expected. Previously, NFKB was identified to exhibit a natural NLS, allowing it to pass through the NPCs and facilitate nuclear transport.

In the present study, a specific DNA targeting sequence (five optimal repeats of NFKB binding motif) was designed and inserted into pDNA to promote nuclear import. Plasmids containing the NFKB binding motif specifically attach to

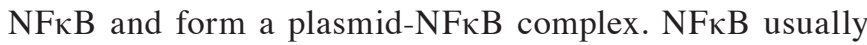
exists as an inactive heterodimer with the I $\mathrm{KB}$ protein (the inhibitor protein of $\mathrm{NF \kappa B}$ ) in the cytoplasm. When cells are stimulated by a specific signal, such as IL-1 $\beta$, the I $\mathrm{K} B$ protein rapidly degrades, activating $\mathrm{NF} \kappa \mathrm{B}$. The NLS of $\mathrm{NF} \kappa \mathrm{B}$ is then recognized by a heterodimeric protein complex importin- $\alpha /-\beta$. Importin- $\alpha$ interacts directly with the NLS and importin- $\beta$ docks the plasmid-NFKB complex to the perinuclear space allowing it to pass through the NPCs (25). As shown in Fig. 5, the majority of the Cy3-labeled phSDF-1 $\alpha$ plasmids were localized in the cytoplasmic space rather than in the nucleus, while the phSDF-1 $\alpha$-NFkB plasmids were predominanltly localized in the nucleus. The quantity of plasmids containing the NFKB binding motif in the nucleus was 6.5-times that of the NFKB-free plasmids following stimulation by IL-1 1 . This indicated that the NFKB binding motif significantly promoted the entry of the plasmid into the nucleus from the cytoplasm. However, without IL-1 $\beta$ stimulation, no significant difference was observed between the $\mathrm{NF \kappa B}$-attached plasmids and the $\mathrm{NF \kappa B}$-free plasmids in the nucleus, suggesting that the $\mathrm{NF \kappa B}$ binding motif cannot function independently of IL-1 $\beta$.

In addition, the protein expression of the SDF-1 $\alpha$ gene was detected. The SDF-1 $\alpha$ protein expressed by HUVECs transfected with phSDF-1 $\alpha-\mathrm{NF \kappa B}$ was $\sim 4$-times greater than that when transfected with phSDF-1 $\alpha$. This result was consistent with the increase of nuclear import, although the expression efficiency was not as high as the efficiency of nuclear import (4- versus 6.5-fold).

In the present study, SDF-1 $\alpha$ was selected as the target gene and HUVECs as the transfection object as numerous studies 
have demonstrated that transfecting the SDF-1 $\alpha$ plasmid into vascular endothelial cells results in the release of SDF-1 $\alpha$. This release facilitated the targeting of circulating CXCR4-positive cells and other stem cells to the site of injury, thus initiating organ regeneration and repair (26-27). Therefore, this study demonstrates a safe and efficient method for promoting SDF-1 $\alpha$ gene transfection, which may be beneficial for numerous types of injuries and diseases.

\section{Acknowledgements}

This study was supported by the National Natural Science Foundation of China (grant no. 302-163534). The authors would like to thank Doctor Jinyue Hu (Central Laboratory of Renmin Hospital, Wuhan University, Wuhan, China) for providing the HUVECs.

\section{References}

1. Elsabahy M, Nazarali A and Foldvari M: Non-viral nucleic acid delivery: key challenges and future directions. Curr Drug Deliv 8: 235-244, 2011.

2. Jafari M, Soltani M, Naahidi S, Karunaratne DN and Chen P: Nonviral approach for targeted nucleic acid delivery. Curr Med Chem 19: 197-208, 2012.

3. Mudhakir D and Harashima $\mathrm{H}$ : Learning from the viral journey: how to enter cells and how to overcome intracellular barriers to reach the nucleus. AAPS J 11: 65-77, 2009.

4. Lentacker I, Vandenbroucke RE, Lucas B, Demeester J De Smedt SC and Sanders NN: New strategies for nucleic acid delivery to conquer cellular and nuclear membranes. J Control Release 132: 279-288, 2008.

5. Pichon C, Billiet L and Midoux P: Chemical vectors for gene delivery: uptake and intracellular trafficking. Curr Opin Biotechnol 21: 640-645, 2010.

6. Kawazu T, Kanzaki H, Uno A, Azuma H and Nagasaki T: HVJ-E/importin- $\beta$ hybrid vector for overcoming cytoplasmic and nuclear membranes as double barrier for non-viral gene delivery. Biomed Pharmacother 66: 519-524, 2012.

7. Burke CW, Suk JS, Kim AJ, Hsiang YH, Klibanov AL, Hanes J and Price RJ: Markedly enhanced skeletal muscle transfection achieved by the ultrasound-targeted delivery of non-viral gene nanocarriers with microbubbles. J Control Release 162: 414-421, 2012.

8. Cool SK, Geers B, Lentacker I, De Smedt SC and Sanders NN: Enhancing nucleic acid delivery with ultrasound and microbubbles. Methods Mol Biol 948: 195-204, 2013.

9. Geis NA, Katus HA and Bekeredjian R: Microbubbles as a vehicle for gene and drug delivery: current clinical implications and future perspectives. Curr Pharm Des 18: 2166-2183, 2012.

10. Zhou Y, Yang K, Cui J, Ye JY and Deng CX: Controlled permeation of cell membrane by single bubble acoustic cavitation. J Control Release 157: 103-111, 2012.
11. Miller AM, Munkonge FM, Alton EW and Dean DA: Identification of protein cofactors necessary for sequence-specific plasmid DNA nuclear import. Mol Ther 17: 1897-1903, 2009.

12. Prasad TK and Rao NM: The role of plasmid constructs containing the SV40 DNA nuclear-targeting sequence in cationic lipid-mediated DNA delivery. Cell Mol Biol Lett 10: 203-215, 2005.

13. Gonçalves C, Ardourel MY, Decoville M, Breuzard G, Midoux P, Hartmann B and Pichon C: An optimized extended DNA kappa B site that enhances plasmid DNA nuclear import and gene expression. J Gene Med 11: 401-411, 2009.

14. Pérez-Martínez FC, Guerra J, Posadas I and Ceña V: Barriers to non-viral vector-mediated gene delivery in the nervous system. Pharm Res 28: 1843-1858, 2011.

15. Xie A, Belcik T, Qi Y, et al: Ultrasound-mediated vascular gene transfection by cavitation of endothelial-targeted cationic microbubbles. JACC Cardiovasc Imaging 5: 1253-1262, 2012.

16. Cavalli R, Bisazza A, Trotta M, Argenziano M, Civra A, Donalisio $M$ and Lembo D: New chitosan nanobubbles for ultrasound-mediated gene delivery: preparation and in vitro characterization. Int J Nanomedicine 7: 3309-3318, 2012.

17. Mehier-Humbert S, Bettinger T, Yan F and Guy RH: Plasma membrane poration induced by ultrasound exposure: implication for drug delivery. J Control Release 104: 213-222, 2005.

18. Glover DJ, Leyton DL, Moseley GW and Jans DA: The efficiency of nuclear plasmid DNA delivery is a critical determinant of transgene expression at the single cell level. Gene Med 12: 77-85, 2010.

19. Allen TD, Cronshaw JM, Bagley S, Kiseleva E and Goldberg MW: The nuclear pore complex: mediator of translocation between nucleus and cytoplasm. J Cell Sci 113: 1651-1659, 2000.

20. Lange A, Mills RE, Lange CJ, Stewart M, Devine SE and Corbett AH: Classical nuclear localization signals: definition, function, and interaction with importin alpha. J Biol Chem 282: 5101-5105, 2007.

21. van Gaal EV, Oosting RS, van Eijk R, et al: DNA nuclear targeting sequences for non-viral gene delivery. Pharm Res 28: 1707-1722, 2011.

22. Cartier R and Reszka R: Utilization of synthetic peptides containing nuclear localization signals for nonviral gene transfer systems. Gene Ther 9: 157-167, 2002.

23. Martin ME and Rice KG: Peptide-guided gene delivery. AAPS J 9: E18-E29, 2007.

24. Munkonge FM, Amin V, Hyde SC, et al: Identification and functional characterization of cytoplasmic determinants of plasmid DNA nuclear import. J Biol Chem 284: 26978-26987, 2009.

25. Jeong JH, Kim SH, Christensen LV, Feijen J and Kim SW: Reducible poly (amido ethylenimine)-based gene delivery system for improved nucleus trafficking of plasmid DNA. Bioconjug Chem 21: 296-301, 2010.

26. Ghadge SK, Mühlstedt S, Ozcelik C and Bader M: SDF-1 $\alpha$ as a therapeutic stem cell homing factor in myocardial infarction. Pharmacol Ther 129: 97-108, 2011.

27. Wen J, Zhang JQ, Huang W and Wang Y: SDF-1 $\alpha$ and CXCR4 as therapeutic targets in cardiovascular disease. Am J Cardiovasc Dis 2: 20-28, 2012. 